\title{
Da emancipação ao autoritarismo: a teoria do pós-materialismo e o "cultural backlash"
}

NORRIS, Pippa; INGLEHART, Ronald. Cultural backlash: Trump, Brexit, and authoritarian populism. Cambridge: Cambridge University Press, 2019.

\section{Julian Borba* (1) \\ Gregório Unbehaun Leal da Silva* (1)}

\section{Resumo}

Cultural Backlash: Trump, Brexit, and authoritarian populism é o mais recente livro de Pippa Norris e Ronald Inglehart. A obra busca analisar transformações recentes nas democracias mais consolidadas, ancorado no modelo teórico originalmente formulado no pós-materialismo. Sintetiza-se aqui essa contribuição, indicando o modo como os autores operacionalizam os conceitos de populismo, autoritarismo e reação cultural. Conclui-se que o modelo Norris/Inglehart foi demasiado otimista e deixou de antecipar fatores como declínio da confiança nas instituições democráticas e da negatividade nas avaliações dos políticos que se consolidaram nos últimos anos. Constatou-se, também, que a obra analisada fornece um original enquadramento teórico para o entendimento da emergência do populismo autoritário nos países estudados.

Palavras-chave: cultural backlash, pós-materialismo, democracia, populismo, autoritarismo.

* Universidade Federal de Santa Catarina, Florianópolis, Santa Catarina, Brasil. 


\section{From emancipation to authoritarianism: the theory of post- materialism and "cultural backlash"}

\section{Abstract}

Cultural Backlash: Trump, Brexit, and authoritarian populism is the latest book by Pippa Norris and Ronald Inglehart. The work seeks to analyze recent changes in more consolidated democracies, anchored in the theoretical model originally formulated in post materialism. In this review, we seek to summarize and explain how the authors operationalize the concepts of populism, authoritarianism and cultural reaction. We conclude that the Norris/Inglehart model was too optimistic and failed to anticipate factors such as a decline in trust in democratic institutions and the negativity in the evaluations of politicians who gained strength in recent years. We also found that the analyzed work provides an original theoretical framework for understanding the emergence of authoritarian populism in the countries studied.

Keywords: cultural backlash, post-materialism, democracy, populism, authoritarianism.

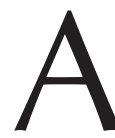

teoria do pós-materialismo pode ser considerada uma das mais ambiciosas construções intelectuais da história das Ciências Sociais, tanto pelo esforço analítico em construir um framework que articula as teorias da modernização e da cultura política quanto pela monumental base empírica do projeto World Values Survey (WVS), pesquisa de opinião pública realizada desde 1980, com amostragens representativas que abrangem quase $90 \%$ da população mundial.

Tanto a base teórica quanto o projeto WVS têm no professor da Universidade de Michigan, Ronald Inglehart, sua grande referência. Tratase de um dos mais citados cientistas sociais da atualidade (Kim; Grofman, 2019), que, ao longo de sua trajetória acadêmica, estabeleceu diálogos com diferentes tradições intelectuais da disciplina. Seu livro The silent revolution, publicado no final da década de 1970, é apontado como obra inaugural desse programa de pesquisa, cujas conclusões apontam para uma lenta e contínua alteração nas prioridades valorativas individuais em nível mundial, que seria resultante, em grande parte, do desenvolvimento econômico experimentado pelas sociedades industriais avançadas a partir 
da segunda metade do século XX (Inglehart, 1977; Inglehart; Welzel, 2009). Em tais contextos, as gerações pós-segunda guerra teriam sido socializadas em ambientes onde a luta pela sobrevivência teria sido em grande parte resolvida, o que possibilitou o desenvolvimento de valores ligados à autoexpressão, como a valorização do meio ambiente e a igualdade de gênero. Dentre as várias consequências desse fenômeno, uma delas seria na dimensão política, com efeitos positivos sobre os processos de democratização (Inglehart; Welzel, 2009).

Pippa Norris tem sido uma das grandes interlocutoras de Inglehart. A renomada professora de Harvard é dona de uma vastíssima obra que recobre campos como mídia e política, recrutamento político, integridade eleitoral e comportamento eleitoral. Parte do seu trabalho estabelece um diálogo com a teoria do pós-materialismo, sendo especialmente importante neste tópico o conceito de "cidadania crítica" (Norris, 1999), que é uma tentativa de explicar importantes mudanças de atitudes e comportamentos do eleitorado das democracias desenvolvidas, como a crescente desconfiança nas instituições democráticas e o declínio na participação eleitoral e partidária. Esse quadro, na interpretação de Norris, não seria um sinal de apatia por parte dos públicos dessas nações, pois, em paralelo à redução na participação eleitoral, estaria ocorrendo um processo inverso nas atividades de contestação às instituições e elites estabelecidas, num desejo de tomar parte dos assuntos públicos de uma maneira mais ativa e direta.

Os diagnósticos de Inglehart e Norris sobre as sociedades democráticas desembocaram em um prognóstico bastante otimista, qual seja, o mundo caminharia para uma preocupação maior com o meio ambiente e com os valores de autoexpressão, para maior participação contestatória, enfim, para democracias mais robustas.

Mas aí vieram os partidos de extrema-direita, que começaram a ganhar força eleitoral na Europa, assim como o Brexit, Donald Trump... e Bolsonaro! E junto com eles, o debate sobre a "crise das democracias", dando origem à pergunta: alguma coisa estava errada nos diagnósticos/prognósticos de Norris e Inglehart ou algo aconteceu na empiria que ocasionou uma mudança de rota em relação ao previsto pelos autores? 
Em Cultural blacklash, Norris e Inglehart sustentam que seus diagnósticos iniciais estavam corretos, mas o mundo mudou! De modo a defenderem seus legados teóricos, vão sustentar a existência de uma intensificação das clivagens culturais nas democracias avançadas, que vai se refletir na emergência das díades pluralismo/populismo e autoritário/libertário; elas são utilizadas como contraposição à tradicional divisão esquerda/direita.

A clivagem esquerda/direita, segundo os autores, é conectada à economic grievances thesis ("teoria das queixas econômicas", em tradução livre), para a qual o destaque político/eleitoral de partidos e líderes autoritários e populistas se dá primordialmente por questões envolvendo crises e flutuações econômicas. Já as outras clivagens estão incorporadas à cultural grievances thesis ("teoria das queixas culturais"), que associa o crescimento desses partidos, líderes e ideias às questões culturais e à retórica populista. A tese dos autores é de que as clivagens culturais têm mais capacidade explicativa que as econômicas (parte 2 do livro).

$\mathrm{Na}$ terceira parte, os autores constroem uma tipologia dos partidos usando as duas clivagens mencionadas anteriormente. O estudo também recai sobre o peso dos sistemas eleitorais nos resultados políticos de partidos populistas-autoritários. Neste quesito, percebem que os sistemas de representação proporcional aumentam as chances eleitorais desses partidos. No entanto, como demonstram na análise do Brexit, os sistemas majoritários não estão "livres" desse risco. Dedicam parte maior da análise para um enfoque à luz das teorias analisadas anteriormente sobre os casos Brexit e a eleição de Donald Trump nos Estados Unidos.

No que se refere ao debate sobre populismo, a obra se distancia do conceito de Mudde e Kaltwasser (2017). Para esses autores, o populismo é uma "thin ideology" ("ideologia rala", em tradução livre). Trata-se de um conjunto de poucas ideias que se apega às ideologias maiores, como liberalismo/socialismo, e produz uma retórica que considera a sociedade separada em dois campos homogêneos e antagônicos - "o povo puro" versus "a elite corrupta" -, onde a política deve ser uma expressão da vontade geral.

Contra essa interpretação, Norris e Inglehart desenvolvem uma análise cujo foco é a retórica discursiva. O populismo teria como característica ser 
"camaleônico": "que pode se adaptar com flexibilidade a uma variedade de valores e princípios ideológicos substantivos, tais como populismo socialista ou conservador, populismo autoritário ou progressista, e assim por diante"11 (tradução nossa, p. 4).

Dois aspectos se destacam nessa formulação mais minimalista adotada em Cultural backlash: i) a única legitimidade possível vem do povo; e ii) os que se encontram no poder são profundamente corruptos e só pensam em si - são, portanto, traidores da confiança pública. "Defendemos que as narrativas populistas podem ser reduzidas a estes - e apenas a estes componentes gêmeos" $^{\prime 2}$ (p. 66). O populismo é oposto ao pluralismo; na avaliação dos autores, ele tem como baluarte a saliência do combate à corrupção e a retórica anti-elite e anti-establishment.

Já o autoritarismo tem como características a conformidade, a segurança e lealdade. Deste modo, a argumentação é a de que apelos autoritários levam a algo próximo de uma relação com um líder tribal, em que se enfatiza a solidariedade de grupos, uma rígida conformação às normas internas e rejeição aos de fora. Esses sentimentos foram, segundo os autores, fortemente mobilizados pelos líderes autoritários nos últimos anos. Nas clivagens por eles construídas, o libertarianismo seria a posição contrária ao autoritarismo. Seria, pois, a junção de populismo e autoritarismo aquela que geraria mais riscos ao regime democrático.

Tomando como base esses dois conceitos, autoritarismo e populismo, e as clivagens acima expostas, os autores constroem seu complexo arcabouço teórico. Nesse quadro explicativo, apontam que o início do processo de reação cultural começa através das mudanças sociais estruturais que se deram no pós-guerra nas sociedades ocidentais mais desenvolvidas. Esse processo continua ocorrendo, em diferentes ritmos, ao redor do mundo. Essa é consequência da riqueza crescente, da expansão da escolaridade, das mudanças dos papéis de gênero, da crescente diversidade étnica e da urbanização.

1 "(...) which can adapt flexibly to a variety of substantive ideological values and principles, such as socialist or conservative populism, authoritarian or progressive populism, and so on". 2 "We argue that populist narratives can be reduced to these-and only these-twin components". 
Seguido a essas mudanças, veio a revolução silenciosa. Esta fez com que, aos poucos, mas de forma constante, uma profunda mudança de valores tenha ocorrido. À medida que as novas gerações foram nascendo, os valores passaram a ser mais pós-materialistas e a visão política mais liberal. Isso ocasionaria, em algum ponto e em dado contexto, um ponto de inflexão. Essa inflexão é fruto da reação dos que não se sentem contemplados pela revolução silenciosa. Em suma, essa teoria afirma que a ascensão do populismo autoritário é a consequência principal de uma reação conservadora contra a "revolução silenciosa" cultural de atitudes socialmente liberais. Nas palavras de Norris e Inglehart (p. 449), "Além disso, o número crescente de pessoas com valores socialmente liberais desencadeou uma reação contrária, à medida que a mudança cultural finalmente atingiu um ponto crítico. A proporção de conservadores sociais diminuiu gradualmente para se tornar uma nova minoria cultural". ${ }^{3}$ Um exemplo de ponto de inflexão seria a eleição de Donald Trump em 2016.

Mas, enfim, quem seria essa "nova minoria cultural"? Das variáveis testadas, a que se mostrou a mais forte preditora do apoio a atitudes autoritárias foi aquela relativa à geração: os mais velhos tendem a dar mais suporte a padrões autoritários, embora o mesmo não se verifique em relação ao populismo. Outro fator que explica o bom resultado de partidos e líderes autoritários é que a geração entreguerras tem aparecido como muito mais propensa a votar do que a geração millenial. Esta lacuna geracional é destacada diversas vezes ao longo do texto. Outros fatores também complementam essa "nova minoria cultural": terem baixa escolaridade, serem brancos, majoritariamente homens e moradores de cidades pequenas ou áreas rurais.

O contexto pessoal e os fluxos migratórios podem acelerar ou retardar esse ponto de inflexão. Desse modo, é possível observar a economic grievances thesis não como rival da cultural grievances thesis, mas como complementar à mesma.

\footnotetext{
3 "Moreover, the rising numbers of those holding socially liberal values have triggered a counter-reaction as cultural change eventually reached a tipping point. The proportion of social conservatives has gradually shrunken to become a new cultural minority".
} 
Na parte final do livro, os autores indicam que, apesar dos abalos recentes, os regimes democráticos continuam consolidados nos países desenvolvidos. Das muitas considerações apontadas, dois aspectos principais nos parecem relevantes. O primeiro aspecto apontado é que "Do lado positivo, além disso, o populismo pode funcionar como uma correção útil para a democracia liberal"4 (p. 421). Nesse momento, os autores sintonizam um argumento similar proposto por Mudde e Kaltwasser (2017), qual seja, o de que as críticas populistas podem auxiliar na mitigação dos problemas apresentados no regime democrático. Essa dimensão "positiva" do populismo, no entanto, irá depender de muitos pormenores e é contextual. No caso de prevalecer queixas mais econômicas, pode ser mais "fácil" responder. Caso a crítica esteja associada a valores autoritários e seja culturalmente engajada, a solução pode ser mais difícil.

O segundo aspecto dialoga com o primeiro e se refere aos eminentes riscos ao consenso democrático liberal, presentes na maior parte dos países estudados: "Na prática, ganhos eleitorais repentinos de partidos e líderes populistas, embora atraiam manchetes, muitas vezes se mostraram voláteis e fugazes. A democracia liberal é uma forma de governo universalmente valorizada pelos cidadãos em todo o mundo e pode permanecer resiliente no Ocidente" ${ }^{\prime 5}$ (p. 421). Dessa forma, os autores apontam tanto para a continuidade da força autoritária-populista quanto para a prevalência dos valores democráticos.

Em que pese a robustez do enquadramento teórico e dos dados empíricos analisados, nossa avaliação é que Cultural Backlash traz à tona os déficits analíticos da teoria do pós-materialismo, especialmente no que se refere ao diagnóstico das democracias contemporâneas. Conforme mencionamos anteriormente, havia ali um grande otimismo com relação à natureza do vínculo que estaria conectando cidadãos e sistemas políticos numa visão totalmente teleológica da história. Porém, o início do século XXI

4 "On the positive side, moreover, populism can function as a useful correction to liberal democracy".

5 "In practice, sudden electoral gains by populist parties and leaders, while attracting headline news, have often proved volatile and fleeting. Liberal democracy is a form of government universally valued by citizens all over the world, and it may remain resilient in the West". 
colocou vários novos desafios para os regimes democráticos. Democracias iliberais, os populismos e os novos autoritarismos são evidências de um quadro, no mínimo, mais complexo do que aquele previsto pelos autores.

No esforço de compreensão da ascensão do autoritarismo e do populismo, faltou a Norris e Inglehart uma autocrítica ao diagnóstico otimista que emergiu a partir de conceitos como "cidadãos críticos" e pósmaterialistas. De fato, os dados sobre o declínio da confiança nas instituições políticas já estavam presentes nestes diagnósticos, os quais, porém, não eram vistos como uma possível ameaça à legitimidade democrática. Se tivessem atentado para este ponto, os autores poderiam ter aventado que tal descrédito nas instituições de representação política já poderia ser um indício de apelo dos eleitores a governos populistas autoritários.

Importante, nesse sentido, retomar a crítica de Mounk (2019) ao destacar que já faz algum tempo que os cientistas políticos estão conscientes acerca do declínio da confiança nas instituições democráticas e da negatividade nas avaliações dos políticos. Entretanto, na obra aqui resenhada, foi destinada muito pouca atenção a estes fatos.

Em que pesem os limites acima destacados, trata-se de um livro fundamental para o entendimento da dinâmica das democracias contemporâneas, especialmente ao fornecer um enquadramento que articula dimensões de longo e curto prazos na explicação da emergência do populismo e da expansão eleitoral dos partidos de extrema-direita no mundo.

Julian Borba é Doutor em Ciência Política, Professor Associado na Universidade Federal de Santa Catarina e pesquisador do CNPq.

$\triangle$ julian@cfh.ufsc.br

Gregório Unbehaun Leal da Silva é Mestre em Sociologia Política e doutorando do mesmo programa na Universidade Federal de Santa Catarina.

$\bowtie$ gregoriosilva1986@gmail.com 


\section{Referências}

1. INGLEHART, Ronald. The silent revolution. Princeton: Princeton University Press, 1977.

2. INGLEHART, Ronald; WELZEL, Christian. Modernização, mudança cultural e democracia. São Paulo: Francis, 2009.

3. KIM, Hannah J.; GROFMAN, Bernard. The political science 400: with citation counts by cohort, gender, and subfield. PS: Political Science $\&$ Politics, v. 52, n. 2, p. 296-311, 2019. http://dx.doi.org/10.1017/S1049096518001786

4. MOUNK, Yascha. O povo contra a democracia. São Paulo: Companhia das Letras, 2019.

5. MUDDE, Cas; KALTWASSER, Cristobal R. Populism: a very short introduction. Nova York: Oxford University Press, 2017.

6. NORRIS, Pippa. Critical citizens: global support for democratic government. Oxford: Oxford University Press, 1999.

7. NORRIS, Pippa; INGLEHART, Ronald. Cultural backlash: Trump, Brexit, and authoritarian populism. Cambridge: Cambridge University Press, 2019.

Recebido em 11 ago. 2020.

Aceito em 26 out. 2020. 